\title{
Modelos de medios cívicos ante la crisis, los casos de Bottup y Triangle
}

\section{Models of Civic Media Against Crisis, Cases of Bottup and Triangle}

José Luis González. Universidad Miguel Hernández

Sergio Martínez Mahugo. Universidad Miguel Hernández

Recibido: 27-X-2009 - Aceptado: 1-I-2010

Resumen:

A pesar de lo novedoso del concepto de periodismo ciudadano existen ya numerosas propuestas para tratar de rentabilizar de un modo u otro este tipo de periodismo y el creciente interés de los públicos por participar en el proceso de la comunicación pública. El presente artículo analiza dos propuestas muy diferentes de medios cívicos singulares: Triangle en EE.UU y Bottup en España. Un vasto trabajo de observación participante en los dos medios nos permite llegar a la conclusión de que ambos creen en el periodismo participativo como fórmula para salir de la crisis del sector, aplicando fórmulas imaginativas donde el ciudadano siempre se sitúa en el centro del proceso comunicacional.

Palabras clave:

Periodismo ciudadano, participación, ciberperiodismo, proximidad, ONG, Bottup, Triangle.

Abstract:

Despite the novel concept of citizen journalism, several alternatives have already been proposed to make profitable this kind of journalism and the increasing interest of the audiences in taking part in the processes of public communication. The following paper analizes two different approaches for participatory mass media: Triangle (USA) and Bottup (Spain). After a deep analysis of both media, we can conclude that they consider citizen journalism to be the formula to get out of the journalistic sectorial crisis, by emphasizing and prioritizing citizens contributions in the communicational processes.

Key Words:

Citizen Journalism, Participation, Ciberjournalism, Proximity, NGO, Bottup, Triangle. 


\section{Introducción: el periodismo ciudadano bien entendido}

El llamado periodismo ciudadano es un concepto polémico desde el momento en el que se usa el sustantivo periodismo para referirse a una disciplina en la que no intervienen profesionales del sector. Así quedó patente en el debate que mantuvieron en el VII Congreso de Periodismo Digital de Huesca celebrado en 2007 los periodistas Javier Monjas y José Cervera ${ }^{1}$. Sea como fuere, y al margen de estos debates terminológicos, lo realmente importante es que nos encontramos ante un fenómeno imparable: la apropiación por parte de los ciudadanos del espacio para la comunicación pública (Varela, 2005: 25).

Las ex audiencias (Gillmor, 2004a: 134) han irrumpido con fuerza en el nuevo entorno para la comunicación pública surgido a raíz de la aparición de las nuevas tecnologías digitales para la información y el conocimiento, y con la popularización de Internet y las redes telemáticas para la distribución de la información. Este nuevo entorno, al que el profesor José Luis Orihuela se refiere como la eComunicación (e-comunicación para Juan Miguel Aguado y otros autores); y Sáez Vacas como nuevo entorno tecnosocial o Manuel Castells como galaxia Internet, se caracteriza por la desintermediación, la hipertextualidad, la interactividad, por la aparición de diversas fórmulas de cooperación y creación colectiva inimaginables hace apenas unos años, por el paso de un panorama de escasez informativa a otro de abundancia y hasta saturación, o la evolución desde un sistema basado en la distribución de la información a otro definido por el acceso libre (Orihuela, 2006: 77).

Internet ha abierto, por tanto, el proceso productivo a los consumidores/usuarios, a los prosumidores a los que se refería Alvin Toffler en La tercera ola (1980) cuando hablaba de individuos que son a la vez productores y consumidores de bienes y servicios, a ese segmento de la población que no se limita a una acción pasiva frente a los medios, sino que prefiere producir y participar, ayudado por las inmensas posibilidades que brindan actualmente las nuevas tecnologías. El mundo digital ofrece nuevas y variadas alternativas para la comunicación pública. Hoy cualquier persona puede usar los medios sociales para manifestarse en el espacio público, ofrecer una voz alternativa a las fuentes informativas oficiales o tradicionales, mostrar su propia visión de las cosas, opinar, enjuiciar, discutir, informar de un suceso o acontecimiento, incluso posicionarse como experto para ser capaz de contextualizar y aportar la mejor explicación sobre un asunto de actualidad (Bowman y Willis, 2003: 14). Eso es periodismo participativo: "El acto de un ciudadano, o un

\footnotetext{
"Los periodistas no tenemos versión, la tienen los coches, los sistemas operativos. El Periodismo 3.0 no existe porque la información no es una democracia, la información es poder y todo el mundo la quiere” (Cercas, 2007. Debate en el Congreso de Periodismo Digital de Huesca). "Si hemos entendido que el mejor modo de gobernarnos es hacerlo entre todos, porque muchas mentes piensan mejor que una, un modelo similar puede aplicarse al periodismo” (Cervera, 2007. Debate en el Congreso de Periodismo Digital de Huesca).
} 
grupo de ciudadanos, con un rol activo en el proceso de recogida, análisis y difusión de noticias e información" (Bowman y Willis, 2003a: 9). Y si el número de actores que compiten por informar, formar y entretener a otros ciudadanos de la mejor manera posible se ha multiplicado exponencialmente, la interactividad que permite el entorno digital llevada hasta sus últimas consecuencias deviene en diálogo. De ahí que el discurso sistemático del nuevo ecosistema mediático dicte que el contenido ya no es el rey absoluto sino que nos debemos regir por una reina que es la conversación. A fin de cuentas, el contenido era la excusa, "era sólo un tema sobre el que conversar" (Doctorow, 2002: 36). ¿O es que acaso nadie ha escuchado nunca, sobre todo a raíz de la popularización de la denominada Web 2.0², eso de que la Red se ha convertido en un gran conversación global? (Fumero, 2007: 16).

Pues bien, todas estas fórmulas para la comunicación pública cuestionan la función tradicional de los periodistas como gatekeepers exclusivos de la información, como inspiradores privilegiados de la agenda-setting, como los depositarios del derecho a la información o como intérpretes únicos de la realidad. Conviene, tal vez, aclarar que ninguno de esos conceptos ha dejado de ser válido pero es necesario afirmar también que hoy debemos entenderlos de una forma mucho más amplia. Con el mundo digital se han derrumbado las barreras económicas y tecnológicas que durante siglos han permitido al periodista asumir en régimen de monopolio la función de informador. En este mismo sentido explica Desantes que se trata de "un compromiso al que se había llegado por delegación tácita de la sociedad ya que es el propio ciudadano el verdadero titular del derecho a informar y ser informado" (Desantes, 1976: 155). En definitiva, dichas barreras permitían igualmente a la empresa periodística rentabilizar económicamente esta tutela.

El periodista no puede ser ajeno a esta realidad si quiere seguir presente en el escenario de la comunicación pública y aspira a continuar jugando un papel privilegiado en el proceso de la información. Tampoco los medios de comunicación tradicionales pueden mantenerse al margen. Y de hecho, no lo están haciendo. Pero su actitud deja mucho que desear. Tanto periodismo ciudadano como participación parece que son las consignas desde el año 2006 para reivindicarse a sí mismos. "De esta forma están destruyendo el fenómeno y reduciéndolo a una mera herramienta de marketing” (Carvajal y Mahugo, 2009).

Sin embargo, ninguna propuesta de periodismo ciudadano debería concebirse exclusivamente a partir de una idea de negocio o de los criterios de la empresa periodística, puesto que se trata de un modelo muy di-

2 El término Web 2.0 fue acuñado en 2004 por Dale Dougherty para referirse al renacimiento que estaba experimentando la Red con la proliferación de unas nuevas reglas, nuevos servicios, nuevos actores y nuevos modelos de negocio. El artículo "What Is Web 2.0. Design Patterns and Business Models for the Next Generation of Software”, de Tim O’Reilly publicado un año después, sienta las bases de este novedoso concepto en el que los medios sociales desempeñan un papel protagonista fundamental. El artículo puede leer en línea en http://www.oreillynet.com/pub/a/oreilly/tim/news/2005/09/30/what-is-web-20.html. 
fícil de rentabilizar. Sólo tiene sentido si se concibe desde la idea del periodismo como función social y con esos objetivos tradicionales ${ }^{3}$.

En realidad, cuando desde las trincheras del periodismo ciudadano se le pide al periodista que sea capaz de escuchar, de involucrarse en la conversación que ya está teniendo lugar fuera de los medios de comunicación tradicionales, en términos de igualdad con su audiencia y sólo si tiene algo interesante que aportar, cuando se espera de él que sea capaz de fomentar un debate social y animar a la participación, que contribuya a superar las brechas digitales existentes y que ayude a la educación de los ciudadanos en valores cívicos, lo que se pretende no es sino tratar de recuperar la esencia de la función social del periodismo y revitalizar la responsabilidad pública del periodista. Una necesidad que ya plantearon entre otros, el filósofo, psicólogo y pedagogo norteamericano John Dewey a principios de siglo XX, los miembros de la Comisión Hutchins y la Escuela de Chicago encargados de redactar el Informe sobre responsabilidad social de la prensa, los mentores del periodismo cívico norteamericano, Carey o Merritt o más recientemente los autores de Los elementos del periodismo, Bill Kovach y Tom Rosenstiel (Kovach y Rosentiel, 2003: 73).

\section{Objetivos y metodología}

El principal objetivo de este trabajo de investigación es demostrar que el periodismo ciudadano bien entendido exige una redacción capaz de conversar en un plano de igualdad con sus usuarios y mantener así el máximo nivel de interactividad posible. Esa misma redacción profesional debe trabajar en la verificación de la información enviada por los ciudadanos puesto que la credibilidad es el criterio más importante que puede revalorizar el trabajo del periodista en un mundo donde cualquiera puede informar y transmitir para una audiencia potencialmente mundial. Por último, la redacción de un periódico ciudadano debe hacer un importante esfuerzo no sólo en la corrección de los materiales informativos que le llegan, sino en la propia educación de los públicos en el manejo de técnicas periodísticas. De igual modo, con el presente trabajo se pretende demostrar que los denominados medios cívicos basados en la participación y relación directa con el usuario son rentables en tiempos de crisis, y son una solución para fidelizar audiencias.

Para desarrollar dichos objetivos y llegar a las conclusiones pertinentes, la metodología de este trabajo de investigación se ha basado en la observación participante, además del estudio del material bibliográfico, todavía escaso, de autores de referencia en cuestiones relacionadas con medios cívicos, periodismo ciudadano

"El periodismo ciudadano es aquel que hace posible la participación activa de los actores sociales que intervienen en todo el procesamiento de la información de interés público. Por lo tanto, sus características esenciales son formar opinión pública mediante la creación de públicos que sean deliberantes y promover la participación ciudadana” (Meso, 2005: 9). 
y participación. En cuanto a la observación participante, cabe destacarse la inmersión en dos medios comunicación, uno estadounidense y otro español. En el caso americano, se trata de Triangle.com, el espacio de participación ciudadana del periódico News \& Observer (Raleigh). Una estancia investigadora permitió el acceso diario al medio referenciado durante un mes, estudiando las rutinas de producción y teniendo entrevistas con los distintos responsables de este periódico centenario. Se trata de un medio que lidera, dentro del grupo McClatchy, los procesos de convergencia de redacciones, así como los proyectos de periodismo online, incluyendo aquí la apuesta por medios cívicos como Triangle, Triangle Mom2Mom o Triangle Jobs. El segundo caso de observación participante tiene que ver con Bottup, en España, medio cívico online de referencia en nuestro país. Dicha observación se ha traducido en cinco visitas a su redacción y entrevistas con su director, Pau Llop, y con los redactores. Estamos hablando, por tanto, de un vasto trabajo de campo que es la base metodológica del presente artículo de investigación.

\section{Periodismo ciudadano, participación y versiones digitales de los medios tradicionales}

Entre los principales retos a los que se enfrentan en la actualidad los medios digitales se encuentra, sin duda alguna, la integración de los contenidos generados por el usuario y la construcción e implementación de herramientas para fomentar la participación de los ciudadanos. El problema es que casi todos los medios suelen afirmar que fomentan la participación ciudadana e implican a sus usuarios en Internet en el proceso informativo-comunicativo cuando en realidad lo que priman son, en general, las estrategias para fomentar el tráfico más que la necesidad de recoger los intereses de los ciudadanos y convertirlos en fuente de primer orden para un periodismo de calidad. Tanto los foros, como los comentarios en las noticias, las encuestas o el envío de fotografías y videos son herramientas que, en realidad, quedan en un segundo plano de la gestión editorial. Por lo general los medios no cuentan con suficiente personal dedicado de forma exclusiva a dinamizar el contenido generado por el usuario. En algunos casos este personal está incluso subcontratado a través de diversas empresas 4 . Por otra parte, la integración del usuario en la dinámica periodística no puede reducirse a una simple medida tecnológica: no basta con poner a disposición del usuario un catálogo de vías para la participación o la comunicación con el medio. La necesaria 'mediamorfosis' (Fidler, 1998: 167) implica mucho más.

Los medios que durante siglos han ejercido el monopolio de la comunicación pública deben cambiar su mentalidad. La incorporación de la interactividad, en toda su dimensión, implica comprender el ejercicio

4 Resulta paradójico por ejemplo que diarios como elpais.com o 20minutos.es no se encarguen de la moderación de comentarios en sus ediciones digitales y sea una empresa externa la que haga este trabajo. 
del periodismo como una conversación. Pero estos medios no están acostumbrados a mantener este tipo de relación con sus públicos. No están entrenados, y tampoco están capacitados ni dimensionados para poder hacerlo. Por eso sólo entienden la interactividad como una cesión de espacios para que su audiencia opine o aporte información sin ninguna contrapartida por su parte (Mahugo, 2006: 8). Y por supuesto, la receta exige una buena cura de humildad hasta que todos los miembros de una redacción sean capaces de aceptar y asumir realmente la vieja máxima de Gillmor que rezaba aquello de que: "Mis lectores saben siempre más que yo" (Gillmor, 2004b: 32). Baste un ejemplo, ¿en qué medio digital tradicional el autor de una noticia se involucra en las discusiones que se generan en los comentarios?

La apuesta por hacer de los medios espacios verdaderamente participativos es cara; exige cambiar rutinas productivas, reorganizar y redimensionar las redacciones, y sobre todo plantea un cambio de mentalidad fundamental.

\subsection{Ciberperiodismo de proximidad, periodismo ciudadano y oportunidades de negocio}

La fortaleza de los medios de comunicación resulta fundamental para el mantenimiento de las sociedades democráticas. En un momento coyuntural como el actual resulta clave que los medios salgan fortalecidos de la crisis global y periodística. En primer lugar, con estructuras y modelos organizativos más ágiles y adaptados a los nuevos tiempos. En este contexto, y en segundo lugar, resulta fundamental la apuesta por capital humano cualificado, independiente, bien formado, ducho en nuevas tecnologías, idiomas y con un amplio sentido ético de la profesión periodística. Solamente la excelencia periodística permitirá una compleja y necesaria reconciliación con los ciudadanos. Nuevos tiempos, nuevos medios, nuevos perfiles profesionales, pero un escenario tradicional y clave en todo este proceso de reinvención o reconversión del periodismo: lo local.

Ya lo decía Maciá Mercader hace algunos años: "A la prensa de regiones se le atribuye el impulso dinamizador del conjunto de la estructura informativa española de nuestro tiempo, muy por encima de lo que en ella incide la llamada prensa central o nacional”, y así sigue siendo a día de hoy (Mercader, 1993: 14). Un maestro como Kapuscinski también ha hablado en diferentes ocasiones de la importancia de lo local ${ }^{5}$.

En definitiva, las nuevas claves para el desarrollo de los medios de comunicación en el siglo XXI pasan por lo local y por Internet, o lo que es lo mismo por el ciberperiodismo local de calidad, algo que están haciendo

5 "Para los periodistas que trabajamos en la gran periferia es muy importante entender que debemos buscar lo universal en cualquier tema, aquello que revela el mundo entero en una gota de agua. Porque una gota de agua contiene el mundo, pero hay que saber encontrar el mundo en una gota de agua" (Kapuscinski, 2005: 37). 
ya grandes corporaciones como The New York Times con sus páginas de información hiperlocal, distribuida por barrios de la ciudad, y en donde el usuario adquiere un papel protagonista que nunca tuvo. Otros grupos norteamericanos centenarios y especializados en la información local, como McClatchy, también están consolidando este proceso de transición. Un estudioso de la comunicación local como el catedrático Xosé López incide en esta precisa idea ${ }^{6}$.

Sin embargo, es notorio que salvo contadas excepciones todavía no ha habido una apuesta por el ciberperiodismo local, como oportunidad para reencontrarse con el ciudadano y entablar una sincera conversación con él, encontrándose todavía en una fase muy inicial en España. Basta como muestra el ejemplo de Elche, la tercera ciudad más importante, en cuanto a población, de toda la Comunidad Valenciana, con más de 240.000 habitantes. Un reciente estudio de la evolución histórica de los cibermedios ilicitanos muestra que Internet es un soporte cada vez más importante para el periodismo local y que su crecimiento es exponencial (Arias, 2009). Un solo apunte sirve para constatarlo: en el último bienio, se han creado dos de los cinco medios que poseen redacción en Elche. Sin embargo, el análisis de sus distintas variables permite subrayar que aún no se ha encontrado un modelo empresarial que los convierta en negocios rentables y que todavía no son capaces de aprovechar las múltiples posibilidades que proporciona la tecnología de la Red de redes.

La observación de su estructura empresarial revela que sólo a uno de los cibermedios se le puede considerar como un medio periodístico real, puesto que el resto se apoyan en empresas distintas, normalmente periodísticas, y basan su funcionamiento en la convergencia multimedia, sin prestar atención a la interacción con el ciudadano. Algunos de ellos, incluso, han optado por no hacer uso efectivo de la publicidad, que hasta el momento es la única fuente de recurso viable en Internet. Además, hay que señalar que la mayor parte de los contenidos se asemejan notablemente al de los medios tradicionales, principalmente a la prensa, en cuanto a temática, estilo y diseño. Pero todavía es más llamativo que la hipertextualidad, la multimedialidad y la interactividad, bases del periodismo en Internet, todavía son conceptos poco explorados y que, a juzgar por su evolución, todavía no se les otorga la importancia que merecen. Por lo tanto, el examen de los cibermedios ilicitanos enseña un panorama con luces y sombras, en el que el tiempo, los movimientos del mercado y, sobre todo, el consumidor, determinarán su auge o su estancamiento, un consumidor-usuario al que todavía no se le coloca en el centro del proceso.

6 La aparición de los cibermedios en esta última década, además de contribuir a la ampliación de la oferta informativa de proximidad y a establecer vías de participación ciudadana, ha abierto nuevos horizontes para el periodismo local (López, 2008: 78). 


\section{El periodismo ciudadano como idea o modelo de negocio según Triangle}

Frente a modelos todavía poco desarrollados en el marco del ciberperiodismo de proximidad en España, nos encontramos fuera de nuestras fronteras otras estrategias acertadas que dan ese necesario protagonismo al ciudadano y que consolidan modelos de negocio a partir de sitios de participación, ocio e información donde el usuario es el eje principal. Es el caso, por ejemplo, del sitio Triangle que forma parte del entramado mediático del News \& Observer, dentro del grupo de prensa regional norteamericano McClatchy. El profesor Francisco Campos Freire incide acertadamente en la necesidad de incorporar las redes sociales al proceso productivo de los medios tradicionales en su vertiente online $\boldsymbol{~}^{7}$. Las marcas piensan que Internet y la Web 2.0 les ayudarán a potenciar su experiencia comercial en un contexto más participativo y proactivo. Es la filosofía de la Web 2.0, convertida en espacio social de comunicación entre distintos usuarios que aprovechan las herramientas informáticas de producción y gestión de contenidos para interactuar e intercambiar contenidos.

Tanto el periódico en papel como la web del News \& Observer están concebidos como periodismo de servicios, sin perder de vista algo que en la prensa norteamericana todavía sigue vigente y es motivo de orgullo: el periódico como watchdog (perro guardián), el periódico como cuarto poder o contrapoder vigilante de las acciones del poder judicial, legislativo y sobre todo del ejecutivo. En nuestro entorno más cercano, tanto en la prensa de ámbito nacional, como en la regional o local, hace tiempo que los periódicos dejaron de cumplir o, al menos, intentar cumplir con dicho cometido. Pues bien, el medio cívico que ha desarrollado el News \& Observer también se plantea bajo esas dos premisas: un espacio de servicios donde el ciudadano adquiera todo el protagonismo, participando de manera activa en la vida social y política de su región, ya sea a través de foros o creándose sus propios blogs en Triangle. Básicamente, a lo que aspira Triangle es a convertirse en una red social de proximidad, referente en todo su territorio. Mariano Cebrián Herreros ha explicado el proceso de democracia horizontal que se está llevando a cabo en muchos medios y que podríamos aplicar perfectamente a nuestro objeto de estudio ${ }^{8}$.

¿Qué es Triangle? Básicamente se trata del medio cívico del News \& Observer, comparable a espacios como La Comunidad ó Yo Periodista (elpais.com), pero con algunos matices diferenciadores. Este espa-

\footnotetext{
"Las redes son un nuevo y atractivo canal que las marcas desean utilizar para reactivar su alicaído branding: escuchar, segmentar, hablar, conversar, movilizar, ayudar, involucrar a los posibles clientes para convertirlos en sus usuarios fieles. Claro que si la estrategia es equivocada, el efecto boomerang será nefasto" (Campos, 2008: 97)

8 "Se pasa de las redes verticales de los medios tradicionales y de gran parte de las ofertas de la Web 1.0 a una democracia horizontal donde todas las partes que se ponen en comunicación se sitúan en igualdad, sin jerarquización alguna y con un intercambio continuo de papeles de emisores y receptores" (Cebrián, 2008: 358).
} 
cio que crea el periódico de manera exclusiva para los vecinos de las áreas metropolitanas de Raleigh, Durham, Chapel Hill y para los condados limítrofes, basa gran parte de su activo en lograr una conversación online efectiva, en tejer una red social, la red de los usuarios y lectores del News \& Observer. El hecho de que el periódico de McClatchy prácticamente no tenga competencia en esta zona del país ha permitido que esa red haya ido cogiendo fuerza con más rapidez. Más allá de una estrategia destinada a lograr buenos posicionamientos en Google (SEO), algo que en España han sabido hacer en momentos puntuales sitios online de periódicos como La Verdad, más allá de esa estrategia que permite ganar visitas a corto plazo, la apuesta por Internet requiere reinventar los productos en función de lo que está demandando el usuario. Y una vez reinventado y lanzado dicho producto, el objetivo primero pasa por consolidarlo y potenciarlo, y para ello, la figura del communtiy manager resulta básica en este tipo de redes o medios cívicos.

El verdadero valor del medio es el usuario, el community manager es un usuario de alto nivel que tiene el liderazgo suficiente para crear y dinamizar comunidades, ya sea a través de los foros, fotoblogs, blogs, etc. En Triangle trabajan varios periodistas del News \& Observer cuyo cometido pasa por captar esos community manager, incentivarlos para aumentar su liderazgo e ir consolidando más usuarios. Además, estos redactores hacen labores de community manager y se encargan de moderar y organizar este espacio ciudadano. Desde la dirección del periódico aseguran que Triangle deriva usuarios a la Web del News \& Observer y que el tejido de esta red ciudadana está permitiendo fidelizar a un público joven que el periódico estaba perdiendo a pasos agigantados durante los últimos años. Más allá de pensar en minutos (SEO), se está pensando en años (el verdadero valor del medio es el usuario que repite). El veterano periodista Dan Barkin es el responsable de la edición online del Observer y tiene claro que sus redactores deben implicarse en esa conversación con el usuario ${ }^{9}$. Otro aspecto destacado del caso analizado es la búsqueda de nichos de especialización más allá del público joven. Triangle ha incorporado durante 2009 dos sitios específicos muy cuidados: Triangle Mom2Mom es un medio cívico para las mujeres de la comarca del Triangle, en Carolina del Norte (Raleigh, Chapel Hill y Durham). Dentro de este nicho encontramos otros nichos como los espacios destinados a la mujer embarazada o a las madres primerizas. Todos ellos siempre con la misma filosofía de espacios de conversación. Además de Triangle Mom2Mom, el equipo de Dan Barkin ha impulsado el pasado año Triangle Jobs que en pocos meses se ha convertido en un espacio de referencia para la búsqueda de empleo y también para el debate. Finalmente, la estrategia del editor on-

9 "Nuestros periodistas participan, son formados en la necesidad de establecer esa conversación con los ciudadanos. Hay una interacción precisa, planificada, hay que saber reconocer a los lectores implicados, a los que se pueden convertir en una fuente e incorporarlos a nuestro espacio específico de participación ciudadana" (González Esteban, 2009: 158). 
line del News \& Observer se ha completado con una mayor presencia en la Web de los nichos de ciberperiodismo de proximidad, esto es Communities donde se agrupan las ocho páginas dedicadas a la información y servicios de los distintos condados de la zona.

Algunos medios realmente creen en las redes sociales, otros simplemente experimentan con presencia en Facebook, Twitter o My space. En el caso que nos ocupa, y buscando otro ejemplo norteamericano como el USA Today, además de tener presencia en dichas redes, se han diseñado plataformas de interconexión e intercambio de contenido multimedia dentro del propio medio, donde los lectores pueden crear perfiles personales y compartir sus propios documentos multimedia, eso es Triangle. Una apuesta de futuro que ya empieza a dar beneficios publicitarios, pero que está planteada como inversión a medio y largo plazo. Toda esta filosofía queda bien resumida por la profesora Tiscar Lara cuando habla de un periodismo social más comprometido $^{10}$.

De igual manera, la profesora Nuria Almirón incide en que el denominado periodismo cívico, periodismo participativo, 3.0 o de base, supone una gestión muy positiva de la interactividad que permiten las nuevas tecnologías al periodismo; aunque matiza con acierto que "la participación ciudadana en los medios de comunicación y la aceptación, por parte de estos, de esta interacción no bastan para atajar la crisis de valores del periodismo" (Almirón, 2006: 61). El motivo de ello es que el verdadero problema del periodismo es su pérdida de credibilidad por su mercantilización, y que la ciudadanía dispuesta a entablar una interacción de carácter intelectual con los medios es, ahora mismo, sólo una elite minoritaria. No tanto, en Triangle, pero sí en la web del News \& Observer, resulta un hecho constatado que todavía son elites las que dominan los espacios de participación.

\section{El medio como ONG: la propuesta de Bottup}

El pasado mes de mayo de 2009 Associated Press anunció ${ }^{11}$ que distribuiría de forma totalmente gratuita artículos de periodismo de investigación entre sus asociados estadounidenses. La propuesta forma parte de un ambicioso proyecto piloto para difundir el trabajo de cuatro organizaciones periodísticas sin ánimo de

10 "En plena crisis de la objetividad como principio, los medios deben arrimarse a los ciudadanos, conocer sus demandas, vertebrar espacios de colaboración para la articulación de iniciativas sociales y dinamizar las comunidades desde un periodismo social más comprometido, y todo esto pasa por construir redes sociales de confianza con sus públicos desde un modelo de participación abierta y de debate democrático en la esfera pública digital" (Tiscar, 2008: 76).

11 HEALD, Emma: "AP to offer its members free investigative reporting pieces from top nonprofits", 15/VI/2009. Disponible en: http://www.editorsweblog.org/newspaper/2009/06/ap_to_offer_its_members_free_investigati.php. 
lucro que trabajan en EEUU. Apenas unos días antes, The Huffington Post, el reconocido portal de blogs, había informado que destinaría más de un millón de euros a una fundación cuyo principal cometido sería facilitar y respaldar el trabajo de la sección de investigación recién creada; el trabajo de los diez periodistas y diversos colaboradores externos contratados puede utilizarse y reproducirse en otros medios. Según Arianna Huffington, la idea surgió ante el temor de que los recortes y cierres de medios puedan dañar la labor investigativa del periodismo, en un momento en que las instituciones públicas necesitan ser vigiladas de cerca. Help Me Investigate es otro proyecto similar en la misma línea. Creado por Paul Bradshaw y respaldado económicamente por la cadena británica Channel 4, este portal permite a los usuarios proponer temas de investigación y al mismo tiempo facilita el trabajo de los propios periodistas a la hora de encontrar información y colaboradores para llevar a cabo las pesquisas. Bradshaw, como Arianna Huffington, también pretende formar parte de un movimiento que recupere los valores tradicionales del periodismo de investigación.

La situación resultaría impensable hace apenas un años, ¿̨o acaso alguien sería capaz de imaginar que la denuncia del escándalo Watergate llegara por teletipo a las redacciones de todos los periódicos norteamericanos al mismo tiempo? Sin embargo, no cabe duda, una de las últimas tendencias en el periodismo de investigación es que la financiación del mismo corra a cargo de las donaciones de la propia audiencia o de los fondos de diversas entidades sin ánimo de lucro. ¿Qué ha cambiado entonces en este tiempo? Muchas cosas. En apenas unas décadas se han transformado los periódicos, la empresa periodística, el modelo de negocio, ha cambiado la actitud y la morfología de los públicos, la tecnología, y por si fuera poco, ahora además se le pide al propio periodismo que se reinvente. Todos estos cambios han coincidido con un periodo de vacas flacas: la crisis de credibilidad de los medios tradicionales y la crisis financiera de la empresa periodística se han conjugado y se traducen, un mes sí y otro también, en reducciones de personal y en constantes rebajas de costes. La calidad y la función social del periodismo son víctimas de los números rojos y las cuentas de resultados.

Bottup es un periódico ciudadano o medio cívico que se publica en Internet desde enero de 2007. Todas las noticias están redactadas por los más de 1.500 usuarios activos que tiene el medio y son verificadas y corregidas por los editores: actualmente tres periodistas licenciados y un equipo de cinco becarios, estudiantes de Periodismo. Bottup fue galardonado en 2008 en los premios ‘Día Mundial de Internet' que concede la Asociación de Usuarios de Internet, por su contribución a la libertad de expresión y su esfuerzo en incorporar a los ciudadanos a la Sociedad de la Información. 
El periodista alicantino Pau Llop, impulsor del proyecto y socio fundador de Nxtmdia lo tiene claro, "el futuro del periodismo no pasa por estructuras empresariales y de lucro"12. Este joven e innovador periodista cree en medios convertidos en plataformas, eso, al menos está desarrollando con Bottup ${ }^{13}$. Este medio no se financia con ningún tipo de publicidad. Lleva funcionando estos dos años exclusivamente con las aportaciones económicas que recibe desde Nxtmdia, una empresa con la estructura jurídica de una sociedad limitada pero que se comporta en realidad como una pequeña Fundación. Por eso, Pau Llop propone hablar de periodismo como si hablásemos de ecologismo o cooperación al desarrollo. Apuesta por un modelo que no se base en la búsqueda del beneficio económico para ningún accionista. Propone un sistema organizativo de la profesión más similar al de las ONG que al de las empresas tradicionales ${ }^{14}$.

Más allá de la forma jurídica que adopte el concepto del medio como ONG, el periodismo sin ánimo de lucro, aboga por la reivindicación de los valores y libertades del hombre, por el derecho universal a la libre información, y por la colaboración activa de los periodistas con los públicos. Para que el periodismo no sólo siga existiendo, sino que mejore como el servicio público que siempre debió ser, existen fórmulas para empezar a trabajar: el crowdsourcing15 y el crowdfunding ${ }^{16}$ que son "las más propicias para salvar al periodista del barco que se hunde” (Llop, 2009b). Por eso, el concepto del medio como ONG casa tan bien con el modelo del periodismo ciudadano.

La labor de Bottup ha traspasado fronteras y recientemente Ashoka ${ }^{17}$ se ha fijado en este proyecto para invertir en él. Ashoka es una organización mundial que identifica e invierte en ideas innovadoras en manos de emprendedores sociales para impulsar cambios estructurales y duraderos. Ashoka ha seleccionado desde

12 Entrevista personal con Pau Llop, realizada el 21/V/2009.

13 "Desde antes de iniciar la aventura de Bottup y hasta el día de hoy creo en un periodismo basado en la comunión entre periodista profesional y ciudadano, en medios que se convierten en plataformas, en lectores que se convierten en usuarios y en una agenda blindada que se convierte en un campo sin puertas. Pero hace ya bastante tiempo que no creo en el periodismo como actividad empresarial" (Llop, 2009a).

14 "Las ONG, si consiguen ser relevantes obtienen financiación por varias vías. Hay algunas ONG con más empleados que el New York Times, donde sus afiliados deciden sobre su acción y estrategia. Además, todo el mundo sabe que las donaciones a ONG desgravan. Grandes bancos y los gigantes de la economía prefieren crear fundaciones para gestionar parte de sus excedentes de capital antes que hacerlos pasar por la caja del Estado; y a través de su estrategia de Responsabilidad Social Corporativa prefieren ser ellos, en lugar del Gobierno, los que decidan que hacer con ese dinero y mucho de ese dinero va a parar a las ONG” (Llop, 2009a).

15 El término 'crowdsourcing' fue acuñado por el escritor Jeff Howe y el editor de la revista Wired! Mark Robinson. Proviene de crowd (multitud) y sourcing (fuente u obtención de una materia prima) y se refiere a aquellas situaciones en las que la participación masiva de unos voluntarios que se autoorganizan sirve para solucionar de manera colaborativa algún problema o llevar a cabo una empresa.

16 De manera similar al crowdsourcing, el crowdfunding se aplica a aquellos casos en los que un grupo de personas voluntarias y autoorganizadas financian de manera conjunta un proyecto.

17 Web del programa Ashoka: http://knowledge.ashoka.org. 
1980 unos 2.000 proyectos de emprendedores, en setenta países de todo el mundo. El proceso de selección es bastante duro. En España sólo se han seleccionado dieciocho de varios campos de conocimiento, por lo que Bottup es el primer y único caso de un proyecto relacionado con el periodismo/comunicación. La beca se enmarca en el programa conjunto de Ashoka con la Knight Foundation, de los Estados Unidos. Básicamente, Ashoka invierte una cantidad mensual en Bottup durante tres años, además del establecimiento de contactos y la pertenencia a su red mundial de becados. Dicha red de emprendedores se reúne y apoya mutuamente, creando sinergias, en este sentido, cabe destacar la presencia de Bottup en la reunión que tuvo lugar en diciembre de 2009, en la Universidad Alpina de McKinsey, en Kizbühel (Austria).

\subsection{Situación actual y objetivos a corto y medio plazo de Bottup}

En la actualidad, Bottup cuenta con 55.549 usuarios únicos/mes (diciembre 2009). Siendo destacable su número de periodistas ciudadanos: 1.274. Los redactores profesionales son tres, con posibilidad de ampliar la plantilla durante 2010. Desde su fundación, Bottup ha editado 4.954 noticias, más de 3.000 procedentes de periodistas ciudadanos. Llegados a este punto y con el apoyo de Ashoka, Bottup pretende crecer bajo una compleja y ambiciosa planificación.

En primer lugar se trata de consolidar un crecimiento orgánico, o lo que es lo mismo, la consolidación de su Consejo Editorial. Bottup se encuentra ahora configurando un Consejo Editorial formado por periodistas, profesores de periodismo, asociaciones periodísticas, sociólogos y otros agentes sociales para conformar un núcleo estable de trabajo diario que descentralice la dirección del medio. Dentro de esta misma estrategia, se enmarca la consolidación de la redacción. Bottup convocará a partir de los próximos meses a todos aquellos periodistas interesados en participar activamente en la redacción editorial diaria, de forma que se puedan asignar temas y áreas geográficas por profesional. El objetivo es que esta nueva estructura sea el germen de la futura descentralización de la redacción y que esta funcione de forma distribuida.

En segundo lugar, Bottup quiere crecer geográficamente, con una estrategia de expansión en Latinoamérica. Uno de los objetivos para 2010 será consolidar una tendencia al alza en los últimos meses: el aumento de la participación de usuarios no españoles, en su mayoría latinoamericanos. El objetivo será potenciar la sección Mundo y que el medio se consolide poco a poco como referente global en cuanto a medio ciudadano, pudiendo acceder cada usuario a un sitio específico en función de su país. Dentro de estas dinámicas, la dirección de este medio cívico tiene el objetivo de la consolidación como emprendimiento social internacional. Tal y como se ha explicado anteriormente, Bottup es el único proyecto español en el programa Ashoka, en el que se encuentran emprendedores internacionales como Jimmy Walles, el fundador de la Wi- 
kipedia. Una idea fundamental para este medio cívico español es mantener su proyección internacional durante los próximos tres años.

Finalmente, nuestro medio objeto de estudio quiere crear una estructura asociativa, y transformarse en una Fundación. Para este 2010 se prevé la creación de una estructura jurídica propia. Se desea optar por la estructura de Fundación, aunque dependerá de la capacidad del proyecto de atraer a los necesarios padrinos económicos. Si no fuese posible, se optará por la estructura tradicional de asociación.

\section{Conclusiones}

a. El presente trabajo de investigación nos demuestra que medios cívicos imaginativos y profesionales representan una buena solución a la actual crisis del sector. En ambos casos se está creando empleo y sus dirigentes prevén una rentabilidad a medio plazo.

b. Los dos casos analizados evidencian que más allá de una moda o herramienta de marketing, Triangle, en Estados Unidos, y Bottup, en España, se creen realmente su papel de intermediación, y basan su estrategia en la conversación real y efectiva con los usuarios. En ambos casos, detectamos redacciones capaces de conversar en plano de igualdad con los usuarios, y editores que destacan que solamente la excelencia permitirá recuperar a los lectores/usuarios.

c. Frente a los casos analizados, vemos que normalmente las versiones digitales de los medios tradicionales apuestan por estrategias encaminadas a fomentar el tráfico a corto plazo sin reparar en recoger los intereses ciudadanos y con redacciones no involucradas en el mencionado proceso de conversación.

d. El caso de Triangle, dentro del News \& Observer del grupo McClatchy, determina que el desarrollo de los medios de comunicación del siglo XXI pasa por lo local y por Internet, en definitiva, por modelos hiperlocales de ciberperiodismo de alta calidad, y por nichos de especialización como en este caso lo son Triangle Mom2Mom, Triangle Jobs o Communities. Invertir a medio y largo plazo en consolidar modelos de negocio a partir de sitios de participación es rentable.

e. Frente al modelo de Triangle, destaca el otro analizado en este trabajo, bien distinto en su concepción y filosofía, ya que Bottup se concibe bajo el concepto del medio como ONG. Ambos recuperan y colocan al ciudadano en el centro del proceso. En el caso de Bottup, los premios recibidos y el mecenazgo de Ashoka ratifican la solidez e innovación de este proyecto singular. 


\section{Referencias bibliográficas}

Almirón, N. (2006): “Los valores del periodismo en la convergencia digital: civic journalism y quinto poder”, Revista Latina de Comunicación Social, n. 61. Disponible en: http://www.revistalatinacs.org/200609Almiron.htm.

Arias, F. (2009): “La evolución del ciberperiodismo ilicitano”, en González Esteban, J.L. (ed.): Informe GICOV sobre el estado de la comunicación en Elx-Baix Vinalopó. Elche (Alicante), pp. 69-80.

Bowman, S. y Willis, C. (2003): We Media. Stanford (California): The Media Center and The American Press Institute.

Campos, F. (2008): “Las redes sociales trastocan los modelos de comunicación de los medios tradicionales”, Revista Latina de Comunicación Social, n. 63, pp. 287-293.

Cebrián Herreros, M. (2008): “La web 2.0 como red social de comunicación e información”, Estudios sobre el Mensaje Periodístico, n. 14, pp. 345-361.

Carvajal, M. y Mahugo, S. (2009): "Herramientas para fomentar la participación ciudadana en las versiones digitales de seis diarios nacionales”, en las actas del XI Congreso Nacional de la Sociedad Española de Periodística (pendiente publicación). Murcia.

Desantes, J.M. (1976): La función de informar. Pamplona: EUNSA.

Doctorow, C. (2002): Essential blogging. Sebastopol (California): O’Reilly Media, Inc.

Fidler, R. (1998): Mediamorfosis. Comprender los nuevos medios. Buenos Aires: Granica.

Fumero, A. y Roca, G. (2007): Web 2.0. Madrid: Fundación Orange.

Gillmor, D. (2004): We the media. Grassroot Journalism by the People for the People. Sebastopol (California): O'Reilly Media, Inc.

González Esteban, J. L. (ed.) (2010): Informe GICOV sobre la comunicación en la provincia de Alicante: comarca Elx-Baix Vinalopó. Alicante: Instituto de Estudios Juan Gil Albert.

González Esteban, J.L.: (2009): “Modelos de periodismo local y estrategias ante la crisis: el caso del News \& Observer”, Revista Latina de Comunicación Social, n. 64, pp.151-160.

Kapuscinski, R. (2005): Los cinco sentidos del periodista. México: Fundación Nuevo Periodismo Iberoamericano.

Kovach, B. y Rosenstiel, T. (2003): Los elementos del periodismo. Madrid: Santillana.

Lara, T. (2008): “La nueva esfera pública, los medios de comunicación como redes sociales”, Telos, n. 76, pp.49-56.

Llop, P. (2009a): “El medio como ONG”, e-contenidos, 10/V/2009. Disponible en: http://www.paullop.es/2009/05/10/elperiodismo-y-el-periodista-el-medio-y-la-ong/. 
Llop, P. (2009b): “El periodismo después del negocio", e-contenidos, 17/V/2009. Disponible en: http://www.paullop.es/ 2009/05/17/el-periodismo-despues-del-negocio-en-el-sicarm-09/

López, X. (2008): Ciberperiodismo en la proximidad. Sevilla: Comunicación Social.

Maciá Mercader, J. (1993): La comunicación regional y local. Barcelona: Ciencia 3.

Mahugo, S. (2006): “La influencia del periodismo ciudadano en los medios tradicionales”, en Sabes Turmo, F. (ed.): Análisis y Propuestas en torno al Periodismo Digital. Huesca: Asociación de la Prensa de Aragón, pp. 318-333.

Meso, K. (2005): “Periodismo ciudadano: voces paralelas a la profesión periodística”, Chasqui, n. 90, pp. 4-13.

Orihuela, J. L. (2006): La revolución de los blogs. Madrid: La esfera de los libros.

Varela, J. (2005): “El asalto de los medios sociales”, Cuadernos de Periodistas, n. 2, pp. 20-34. 